\title{
Study of the possibilities of 3D printing in ship modeling using the example of manufacturing a model of a small vessel for hydrodynamic testing in an experimental pool
}

Alexander Vladimirovich Dektyarev ( $\nabla$ nwasanches@mail.ru )

Kaliningradskij gosudarstvennyj tehnicheskij universitet https://orcid.org/0000-0002-3756-7233

Pavel Gennadievich Zobov

Institut sudostroenija i morskoj arkticheskoj techniki

Pavel Romanovich Grishin

Kaliningradskij gosudarstvennyj tehnicheskij universitet

Vladimir Nikolaevich Morozov

Kaliningradskij gosudarstvennyj tehnicheskij universitet

\section{Original Article}

Keywords: 3D printing, additive technologies, ship modeling, pilot pool, hydrodynamics, towing resistance, 3D scanning, glue, strength, polylactide

Posted Date: April 7th, 2020

DOI: https://doi.org/10.21203/rs.3.rs-20833/v1

License: (c) (1) This work is licensed under a Creative Commons Attribution 4.0 International License.

Read Full License 


\section{Abstract}

The relevance of the work is determined by a fundamentally new direction of 3D printing in the manufacture of ship models for hydrodynamic testing. In this paper, we study the towing drag of a model of a small boat manufactured using additive three-dimensional printing technologies. Based on the dimensions of the 3D printers used and the technological parameters of working with them, as well as the design features of the test pool, small-sized vessels of a series of kayaks, kayaks and canoes, which are of sufficient length, but not too wide and high, were investigated as a prototype of the future model, which is ideal under the methods of additive manufacturing. A base of prototypes of vessels of this class has been compiled and a rationale has been given for the choice of the prototype vessel itself for research, including an analysis of the design of the vessels presented, the availability of design and technological documentation, as well as technological schemes for manufacturing the model. A 3D model of the vessel was developed, its optimization for 3D printing and analysis of geometric shapes for deviations from ITTC requirements. The study of deviations of the geometric shapes of the ship model from shrinkage deformations was carried out using 3D scanning with the development of a technological scheme for describing this process. When developing a 3D model, in the process of 3D printing, as well as processing the results of 3D scanning, modern software tools - FreeShip, Autodesk Inventor, Cloud Compare, and others - were used in the work. In the manufacture of the model, the new DPA adhesive compound formula was used, able to provide durable joints for PLA plastic products. It was found that the measurements prove the possibility of using 3D printing for the production of ship models for hydrodynamic testing, subject to all the nuances of the technology.

\section{Introduction}

Today additive technologies are an important component of the modern production cycle. With the expansion of the product range, traditional printing technologies are being replaced by 3D printing, which, together with an analysis of the applicability of marine engineering to additive manufacturing, raises the question of further possible ways to use rapid prototyping technologies in the shipbuilding industry. 3D printing in ship modeling is a fundamentally new and dynamically developing area that requires a lot of research, both experimental and theoretical, and analytical research.

Some studies on this subject have already been carried out [1-3], but the presented work covers a wide range of issues that have not been studied before, in particular, issues of studying print accuracy, issues of model strength, issues of agreement between experimental data and simulation data.

The overall goal of the work is to conduct an experimental study of the towing resistance of a model of a small vessel manufactured using additive technologies. For its implementation, the study is divided into several sections: development of a 3D model of a prototype vessel and its optimization for 3D printing, development of model manufacturing technology and strength experiment, verification of printing accuracy by 3D scanning methods for compliance with international standards of the International 
Towing Tank Conference (ITTC), hydrodynamic tests in the experimental pool and simulation in the FreeShip software packages using the KAPER method and in MichletPro.

\section{Development Of A 3d Model Of The Selected Prototype Vessel And Its Optimization For 3d Printing}

In this work, in view of the dimensions of the 3D printers used, as well as the design features of the experimental pool, a small vessel with a sufficient length, but not too wide and high, was used as a prototype. This is to avoid unnecessary bonding of parts of the vessel after printing. Therefore, vessels such as kayaks or canoes may be suitable as prototype vessels.

As a result, a base consisting of the $31 \mathrm{st}$ vessel was assembled and studied (table 1), and based on their design, the availability of design and technological documentation, the dimensions of the experimental pool and the equipment used, it was decided to choose a prototype of the vessel.

Table 1. Basic data on the vessels under study 


\begin{tabular}{|c|c|c|c|c|c|}
\hline Title & Length, m & Width, m & Board height, $\mathrm{m}$ & Corp weight, kg & Load capacity, kg \\
\hline Speed tourist kayak «Akula» & 5.7 & 0.7 & 0.35 & 35 & - \\
\hline Kayak loner of class $\square 1$ & 4.0 & 0.6 & 0.3 & 13 & - \\
\hline Slalom canoe deuce of class LS- $₫ 2$ & 4.6 & 0.8 & 0.35 & 20 & - \\
\hline Fiberglass kayak «Nerl'» & 5.41 & 0.84 & 0.40 & 35 & - \\
\hline Fiberglass kayak «Nerl'-R» & 4.95 & 0.77 & 0.35 & 35 & - \\
\hline Canoe «Taimyr» & 4.5 & 1.0 & 0.57 & - & 250 \\
\hline Single lighter canoe «Runabout» & 4.9 & 0.9 & 0.35 & - & - \\
\hline Aleutian kayak «CKF» & 5.1 & 0.5 & 0.3 & - & - \\
\hline Traditional Aleutian kayak & - & 0.5 & 0.3 & - & - \\
\hline Round canoe «Cinderella» & 3.65 & 0.76 & - & - & - \\
\hline Flexible kayak & 5.0 & 0.75 & 0.35 & - & - \\
\hline Kayak «Iskra» & 4.8 & 0.82 & 0.30 & 40 & 250 \\
\hline Kayak «Taimen'-2» & 5.0 & 0.85 & 0.27 & 24 & 250 \\
\hline Kayak «Taimen'-3» & 5.7 & 0.88 & 0.27 & 29 & 375 \\
\hline Kayak «Salyut 4,7» & 4.7 & 0.88 & 0.27 & 31 & 250 \\
\hline Kayak «Salyut 5,2» & 5.2 & 0.98 & 0.27 & 35 & 350 \\
\hline Kayak «RZ-85» & 5.5 & 0.86 & 0.27 & 32 & 250 \\
\hline Kayak «Neptun» & 5.5 & 0.75 & 0.24 & - & 250 \\
\hline Slalom kayak & 4.0 & 0.6 & 0.17 & 11,5 & - \\
\hline Slalom kayak «Hartung» & 4.0 & 0.61 & 0.2 & - & - \\
\hline «K1» by K. Shtals and R. Trachulis & 4.0 & 0.6 & 0.18 & 13 & - \\
\hline Singles by M. Dolbenko and N. Sazonov & 3.7 & 0.67 & 0.21 & 13 & 125 \\
\hline «Bolivar» by V. Strogonov & 3.6 & 0.65 & - & 1,5 & - \\
\hline Singles by V. Melnikov & 3.4 & 0.72 & 0.21 & 12 & - \\
\hline «Strela» by P. Ustinov & 3.6 & 0.72 & 0.25 & 13 & 125 \\
\hline «Sirena» by V. Grushevskiy and G. Nichkov & 4.0 & 0.65 & 0.2 & 16 & 140 \\
\hline Kayak byN. Pankratov & 3.9 & 0.72 & 0.26 & 19 & 150 \\
\hline «Sever» by P. Ustinov & 4.2 & 0.75 & 0.27 & 19 & - \\
\hline «Cayman» & 3.9 & 0.69 & 0.27 & 16 & 125 \\
\hline «Hartung» & 4.0 & 0.6 & 0.21 & - & - \\
\hline «Nord» by M. Dolbenko & 4.3 & 0.7 & 0.21 & 18 & - \\
\hline
\end{tabular}

The prototype of the study selected fiberglass kayak "Nerl"'. The theoretical drawing of the kayak is shown in Figures 1 (side and half-latitude) and 2 (body).

The development of the 3D model was carried out in FreeShip. The model was manufactured on a 1:5 scale. As a result of the development of the 3D model, it was found out that some parts of the surface cannot be deployed on a plane (Fig. 3, green color) and cannot be deployed on a plane (Fig. 3, red color). Therefore, using traditional methods to make such a case is a rather laborious and costly task.

Based on the experience of model workshops for the manufacture of ship models for testing in test pools, it is worth noting that prototypes can be made in 1-2 weeks, but the period can be increased if the model needs to be developed from scratch. Production time usually depends on the features of the model, its scale, material, the need for picking with interactive elements. For testing in test pools, the main thing is the accuracy of the shape of the contours. Therefore, the issue of model detailing is an important system- 
forming link in ship modeling. In leading European model workshops at test basins, the manufacture of a similar model of a prototype vessel is estimated at $\approx € 6500$.

\section{Development Of Model Manufacturing Technology And Strength Experiment}

According to the recommendations specified in the international requirements for ship models to be tested in test pools $[4,5]$, models should be puttied, painted and varnished before the tests themselves.

Printing of the model was carried out on an AnetA6 3D printer made of PLA plastic from 5 blocks (Fig. 4). One spool of thread with a cost of $\approx € 15$ was used up for printing. Production time -5 days (when using one 3D printer), taking into account the bonding of parts of the model and the complete hardening of the adhesive joints.

Bonding of individual parts is the most common method of assembling large and medium-sized products grown using 3D printing methods [6-8]. Therefore, the blocks of the model were glued together using the developed adhesive composition «DPA» for polylactide.

Adhesive «DPA 10/2» is a mixture of polyvinyl butyral, dichloroethane and polylactide (1), connected by ultrasound technology of mechanical resonant mixing:

$\mathrm{C}_{2} \mathrm{H}_{4} \mathrm{Cl}_{2}+\left(\mathrm{C}_{8} \mathrm{H}_{14} \mathrm{O}_{2}\right)_{\mathrm{n}}+\left(\mathrm{C}_{3} \mathrm{H}_{4} \mathrm{O}_{2}\right)_{\mathrm{n}}$

Adhesive «DPA 10/1» is a mixture of dichloroethane, polylactide and acetone, connected by the same technology (2):

$\mathrm{C}_{3} \mathrm{H}_{6} \mathrm{O}+\left(\mathrm{C}_{3} \mathrm{H}_{4} \mathrm{O}_{2}\right)_{n}+\mathrm{C}_{2} \mathrm{H}_{4} \mathrm{Cl}_{2}$

The main difference between «DPA/2» and "DPA/1» adhesives is that in the second case, because of the use of acetone, there is no precipitate that affects the shelf life of the adhesive, which is important for long-term storage and transportation.

The strength properties of the joints bonded with the following adhesives were investigated: «Zvezda» adhesive for plastic, «Moment Classic» universal waterproof adhesive, «DPA 10/1» adhesive, and «DPA 10/2» adhesive. The tests were carried out in the research, technological and testing center of JSC "Production Association" Sevmash" in Severodvinsk. The test procedure and the shape of the samples were in accordance with the standard [9] (Fig. 5).

As a result:

1. "Zvezda» adhesive for plastic. The joints were destroyed immediately after the start of the tests; accordingly, the machine did not fix the strength characteristics. The compound has low strength 
properties. Glue can not be used when gluing critical products.

2. Universal waterproof adhesive «Moment Classic». The sample immediately began to diverge along the seam. The destruction of the compound occurred after a sufficiently large deformation. Tensile Strength $=18.9 \mathrm{~N}$.

3. Adhesive "DPA». The destruction of the seam did not occur, the layers of the sample burst at the point of transition of the sections. The average yield strength $=421.4 \mathrm{~N}$, the destruction of the plastic itself did not occur at the glued joint.

The difference in tensile strength between the two adhesives was $95 \%$ in favor of glue brand «DPA».

The model, after gluing the blocks, is shown in Figure 6. The glued, putty and painted model is shown in Figure 7.

\section{Verify Print Accuracy Using 3d Scanning Methods}

Scanning of the obtained physical model was carried out using an optical 3D scanner 3D Systems Sense $2 \mathrm{nd}$ gen with a declared deviation of this measuring equipment of $1 \mathrm{~mm}$ under ideal conditions. The geometric deviations of the physical model from its 3D image were checked based on the requirements of $[4,5]$

The sample grid was obtained by saving the original model for printing in STL format. The average deviation of the grid geometry, measured by means built into Autodesk Inventor, is $0.4 * 10^{-5} \mathrm{~mm}$. This level of accuracy is acceptable for comparing a grid-sample with a grid-scan and exceeds the accuracy of measuring equipment.

According to the experience of working with scanning equipment in the optical range, the optimal lighting mode was selected - LED warm light lamps. Such a light source gives a minimum of radiation in the IR range and favorably affects the measurement accuracy due to the absence of spurious illumination, bringing the instrument closer to a laser scanner working with completely monochrome illumination, while maintaining the main advantage of optical scanners - the ability to work with objects of almost any color without noticeable distortions.

To get the most detailed data, all additional Sense software features (texturing, automatic recognition, resolution ranking) were disabled, and the resolution and data buffering were increased to the maximum allowable for the equipment. This approach allows you to get more accurate data about the surface, but increases the processing time due to the ingress of foreign objects into the scan area. 
Errors associated with shrinkage of the filament were taken into account on the basis of measurements of a total of 32 test cubes in $1 \mathrm{~cm}^{3}$. The geometric error when slicing the model is minimal due to the absence of thin walls. The most difficult areas of processing are the nose and feed.

The grid obtained after removing noise and background is shown in Fig. 8. The total amount of scan data is $4.6 \mathrm{~Gb}$.

No methods of smoothing the mesh and automatic noise cleaning were used, which guarantees accurate transmission of the geometry of the physical model. Grid deviations were compared using Cloud Compare software. The grid of the model and the grid of the scan was combined in two stages - a rough initial alignment at five points on the surface manually and precise alignment using the finely register meshes tool. Automatic alignment was carried out with the double precision criterion using 1500 iterations, at 4678 points on the scan surface and model. The presented settings indicate explicit mathematical redundancy and exclude alignment errors. The final diagram of surface and plot deviations obtained after alignment is shown in Figs. 9-11.

Processing of the scan data allowed us to determine that the maximum deviation in the positive direction is $0.45 \mathrm{~mm}$, and in the negative $-0.54 \mathrm{~mm}$. For a more understandable estimate, we present the Gaussian distribution (Fig. 12).

From this diagram it can be seen that the standard deviation was $0.25 \mathrm{~mm}$.

Based on the requirements of $[4,5]$ for model testing of vessels, the maximum tolerance along the $Z$ axis (draft) should not be more than $1 \mathrm{~mm}$. According to the histogram and plot, we see that in the direction of the $Z$ axis, the main plane of the bottom has a deviation of no more than $-0.2 \mathrm{~mm}$, which, taking into account the measurement error, indicates that the requirements on the $Z$ axis are fulfilled. The length tolerance is $0.05 \%$ of the length between perpendiculars, which in our case is $2.7 \mathrm{~mm}$, therefore, this requirement is also successfully fulfilled.

\section{Hydrodynamic Tests In The Experimental Pool And Simulation}

Towing tests were carried out in a gravity-type test basin at the Institute of Shipbuilding and Marine Arctic Engineering in Severodvinsk. As a study of the hydromechanical qualities, it was necessary to conduct an experiment to determine the towing resistance of a model of a vessel in quiet water when landing without heel (straight) and on an even keel (without trim) with a speed range of 1-5 knots. Recalculation of model test data was performed in accordance with [10]. The roughness of the hull of the model is taken conditionally equal to the roughness of the full-scale vessel. Tests were carried out according to the Froude number.

Simulation was carried out according to the KAPER method in FreeShip and in Michlet Pro software. 
The KAPER resistance method is intended for canoes and kayaks. It was originally developed by John Winters, a naval architect now specializing in designing canoes and kayaks. It is based on statistical data obtained by model tests [11].

Michlet - is a computer workbench than can be used for investigation into some aspects of ship hydrodynamics. Although it is not a ship design program, Michlet can be used for preliminary design work such as estimating the resistance, wave elevation patterns and bottom pressure signatures of monohulls, multihulls and submarines [12].

The model of the vessel during testing is shown in Fig. 13.

The results of the towing tests of the ship model in the test pool are shown in Fig. 14. Here, the resistance of the vessel $R$ is divided into two components: the friction resistance $R_{f}$ and the residual resistance $R_{r}$. The resistance $R_{f}$ is assumed to be equal to the resistance of the equivalent plate of the same length and area of the wetted surface as the full-scale vessel.

The results of simulation using the KAPER method (a graph of the resistance versus model speed) are shown in Fig. 15.

At the same time, in Fig. 15 are indicated (resistance values are given in $\mathrm{N}$ ):

$R_{f}$ (blue line) - friction resistance;

$\mathrm{R}_{\mathrm{r}}$ (green line) - residual resistance;

$\mathrm{R}_{\mathrm{t}}$ (red line) - impedance;

Spilman (black line) - impedance according to Spilman (residual resistance, in this case, is the simplest relationship, based only on the speed / length ratio of the project, and is included to give the user a point for reference).

The simulation results in Michlet Pro are shown in Figs. 16-24.

Where:

$R_{v}$ - viscous resistance;

$\mathrm{R}_{\mathrm{f}}$ - skin friction;

$R_{\text {form }}-$ form frag;

$\mathrm{R}_{\mathrm{w}}$ - wave resistance;

$R_{w t r a n s}$ - wave resistance of transverse wave system; 
$\mathrm{R}_{\mathrm{wdiv}}$ - wave resistance of diverging wave system;

$\mathrm{R}_{\mathrm{h}}$ - hydrostatic resistance on transom stern;

$\mathrm{R}_{\text {lee }}$ - resistance due to leeway.

Beta (degrees) - ship drift angle;

Theta - angle of inclination;

$d R / d T h e t a-$ spectrum of free waves.

Based on the results of simulation, the following conclusions can be drawn:

1. The shape resistance of this model is minimal.

2. There is no transom resistance $R_{t r}$ (no explicit transom), protruding $R_{a p p}$ protruding parts, bulb resistance $R_{b}$ and wind resistance $R_{\text {wind }}$.

3. The total wave impedance $R_{w}$ has a complex profile due to the superposition of the bow and stern waves, and the point where they mutually cancel out is important.

4. On the graph «Total resistance components» it can be seen that for this building there are pronounced points of the «economic course» in the places where the wave resistance decreases.

\section{Conclusion}

These measurements prove the possibility of using 3D printing for the production of ship models for hydrodynamic testing, subject to all the nuances of the technology. The main deviations of the geometry in the model are explained by seams during gluing, as well as by the complexity of processing and grinding of putty layers in the fore and aft ends due to the complex surface curvature.

Manufacturing models for testing using additive technology is a less costly and time-consuming procedure compared to traditional forms of ship modeling. Shrinkage deformations, in the considered version, are included in the tolerance field in accordance with international recommendations for the manufacture of ship models and hydromechanical tests in test pools, and have little effect on the results of experiments that can be neglected.

The use of a new adhesive composition with higher strength characteristics, in comparison with traditional brands of adhesives for plastics (the value of the tensile strength of glue "DPA" is higher by 95\%) makes the model strong and durable.

The use of additive manufacturing technology instead of using traditional methods for manufacturing ship models allowed the following conclusions: 
- the nomenclature of marine engineering facilities suitable for additive production has expanded significantly and continues to grow;

- the manufacture of ship models using 3D printers is a more economical and less time-consuming production compared to traditional methods of manufacturing the tested models;

- the use of polylactide as a manufacturing raw material is the most environmental solution due to the biodegradability of this material;

An analysis of the test results in the experimental pool shows that in the case of a model experiment, from the calculation of equivalent plates, it follows that the friction resistance is negligible, and this significantly affects the results of simulation. Most of the resistance is shape and wave. Recalculation of the model experiment in the Froude experimental pool reflects wave formation much better. The Kaper method, based on statistics obtained from model tests of canoe, kayak and kayak series, practically does not take into account wave formation. Michlet calculation gives more realistic results on wave formation.

\section{Abbreviations}

ITTC - International Towing Tank Conference

DPA - new adhesive compound formula for polylactide productions

PLA - polylactide

$\mathrm{m}$ - meters

$\mathrm{kg}-$ kilogram

JSC - Join-Stock Company

$\mathrm{N}$ - Newton (unit of force in the International System of Units)

STL (stereolithography) is a file format widely used for storing three-dimensional models of objects for use in additive technologies.

$\mathrm{mm}$ - millimeters

IR - infrared

$\mathrm{cm}$ - centimeters

LED - Light-emitting diode

Gb - gigabyte 


\section{Declarations}

\section{Availability of data and materials}

Data availability is presented in a separate document.

\section{Competing interests}

The author Alexander Vladimirovich Dektyarev declares that he have no competing interests.

The author Pavel Gennadievich Zobov declares that he have no competing interests.

The author Pavel Romanovich Frishin declares that he have no competing interests.

The author Vladimir Nikolaevich Morozov declares that he have no competing interests.

\section{Funding}

The study was carried out thanks to the financial support of the Foundation for the Promotion of the Development of Small Forms of Enterprises in the Scientific and Technical Sphere under the program "participant in the youth scientific and innovative competition», contract no. «13558ГУ / 2018 dated $07 / 23 / 2018$ », project «Development of the technology for manufacturing the hull of the vessel additive methods».

\section{Authors' contributions}

Alexander V. Dektyarev.

Alexander Dektyarev financed the research, the idea of work belongs to him, developed methods and procedures for the work performed. He developed a base of prototype vessels, examined each vessel and selected a vessel prototype for further research, developed its 2D drawing and 3D model.

Pavel G. Zobov.

Pavel Zobov printed the model of the vessel, conducted a 3D scan of the rim of the model of the vessel, conducted a strength experiment to determine the tear-off force of the new adhesive composition, conducted hydrodynamic tests in the experimental pool.

Pavel R. Grishin.

Pavel Grishin conducted simulation in FreeShip software packages using the KAPER method and in the software of Michlet Pro.

Vladimir N. Morozov. 
Vladimir Morozov is the scientific director of the project. He helped in the preparation of the glue formula, developed the technology for its manufacture, and also selected materials based on his early research on the strength of thermoplastics.

\section{Acknowledgements}

Thanks to:

Dmitry A. Romanyuta (Kaliningrad State Technical University, Head of the industrial laboratory for operational strength of fishing vessels) - for help in hydrodynamic tests.

Igor I. Nikolaev (Kaliningrad State Technical University, engineer of the shipbuilding research center) - for help in developing a 3D model and its optimization for 3D printing.

\section{Ethics approval and consent to participate}

Not applicable

\section{Consent for publication}

Not applicable

\section{References}

1. Kloske, R., Josten, M., \& Carstensen, B. (2019). Resistance tests with 3D printer models in the early ship design stage of high speed vessels. Proceedings of the 18th International Congress of the International Maritime Associations of the Mediterranean (IMAM). Sustainable Development and Innovations in Marine Technologies. Marine Technology and Ocean Engineering Series Volume 3, 150-156.

2. de Morales, C.C., \& Santiago, R.C. (2018). AUV Scaled Model Prototyping using 3D Printing Techniques. 2018 IEEE/OES Autonomous Underwater Vehicle Workshop (AUV), 1-6.

3. Bennett, S.S., Downes, J., Dickson, T., Phillips, A.B., \& Turnock, S.R. (2015). Rapid Prototyping of Flexible Models - A New Method for Model Testing? 7th International Conference on Hydroelasticity in Marine Technology, 1-12.

4. ITTC, 2002. «Ship Models», 23rd International Towing Tank Conference, Vehicle, ITTC Recommended Procedures, Procedure 7.5-01-01-01, Rev. 01.

5. ITTC, 2002. «Resistance uncertainly analysis, example for resistance test», 23rd International Towing Tank Conference, Vehicle, ITTC Recommended Procedures, Procedure 7.5-02-02-02, Rev. 01.

6. Chen, X., Zhang, H., Lin, J., Hu, R., Lu, L., Huang, Q., Benes, B., Cohen-Or, D., \& Chen, B. (2015). Dapper: Decompose-and-Pack for 3D Printing. ACM Transactions on Graphics (TOG), 34(6), 12.

7. Allard, T.T., Sitchon, M.L., Sawatzky, R., \& Hoppa, R.D. (2005). Use of Hand-held Laser Scanning and 3D Printing for Creation of a Museum Exhibit. The 6th International Symposium on Virtual Reality. 
Archaeology and Cultural Heritage, 8-11.

8. Wei, X.R., Zhang, Y.H., \& Geng, G.H. (2016). Non-infill 3D Printing. 3D Research, 7(3). 12.

9. ISO 6922:1987. Adhesives - Determination of tensile strength of butt joints.

10. Voytkunskiy, Ya.I. (1985). Spravochnik po teorii korablya: v trekh tomakh. Tom 1 (Handbook of ship theory: in three volumes. Volume 1). Leningrad. 1985. 768 p. In Russ.

11. FREE!shipmanual. Version 2.6. 2006. pp. 57. www.freeship.org

12. MICHLET User's Manual. 2010. Cyberiad. pp.35.

\section{Figures}
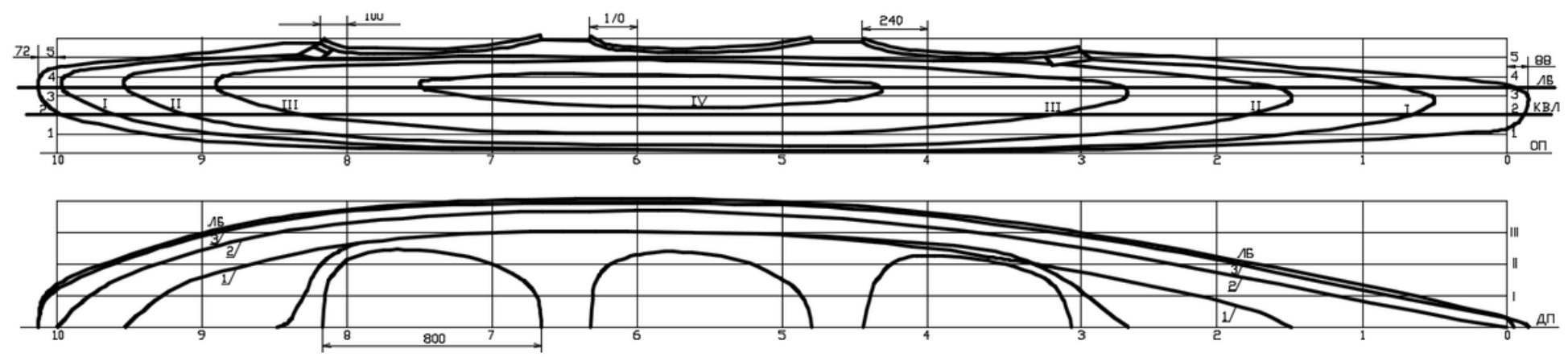

Figure 1

Theoretical drawing of a kayak "Nerl'" (projections - side and half-latitude)

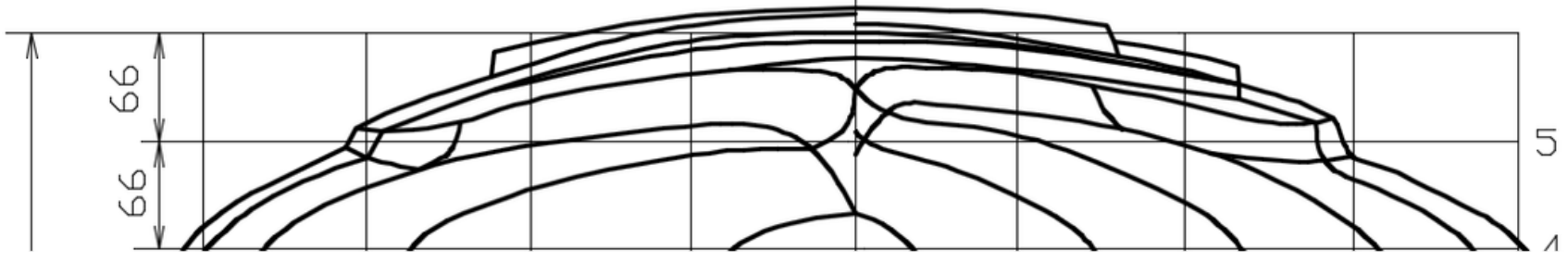

Figure 2 
Theoretical drawing of a canoe "Nerl"' (projection - hull)

Figure 3

3D-model of the vessel with the analysis of the technological form of the hull

Figure 4

Model blocks

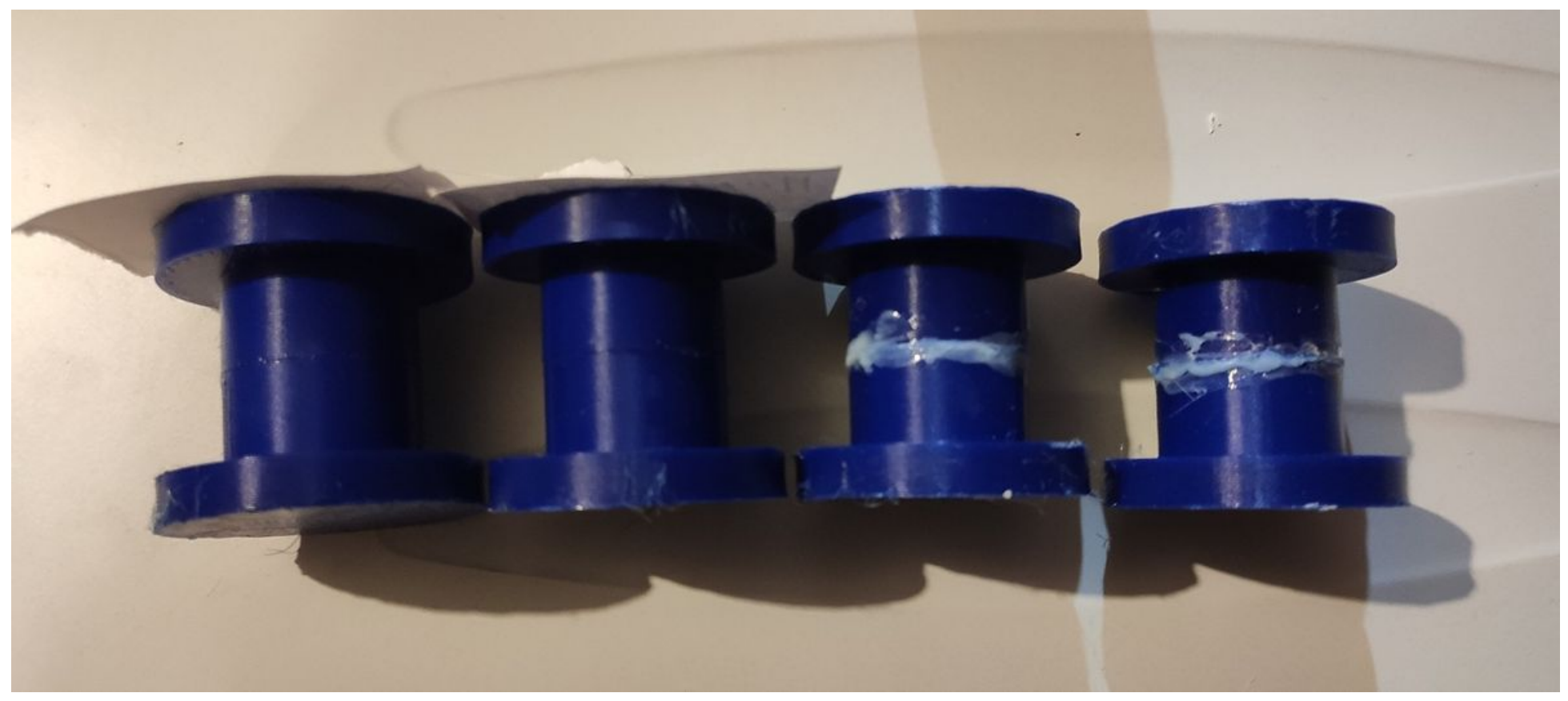

Figure 5

Glued samples for testing

Figure 6

Model after gluing blocks

Figure 7

Ready to test model

Figure 8 
Grid scan after pre-processing

\section{Figure 9}

Diagram of geometry deviations in the scanning area

\section{Figure 10}

Histogram of deviation distribution (maximum deviation in "-" is shown)

\section{Figure 11}

Histogram of deviation distribution (maximum deviation in " + " is shown)

\section{Figure 12}

Gaussian distribution histogram

\section{Figure 13}

Carrying out towing tests

\section{Figure 14}

The results of experimental studies in the experimental pool

\section{Figure 15}

KAPER simulation results in FreeShip

\section{Figure 16}

Spectrum of free waves

\section{Figure 17}


Dependence of the drift angle $\beta$ of the vessel on the inclination angle $\theta$

\section{Figure 18}

Wave amplitudes

\section{Figure 19}

Wave resistance components

\section{Figure 20}

Wave formation behind the body

\section{Figure 21}

Longitudinal section of waves

Figure 22

Viscous resistance components

\section{Figure 23}

Total resistance components

\section{Figure 24}

Total resistance

\section{Supplementary Files}

This is a list of supplementary files associated with this preprint. Click to download.

- Availabilityofdataandmaterials.rar 